\title{
Jatropha Multifida Poisoning In A Malabari Goat
}

\author{
Sulficar, $\mathrm{S}^{1}$ and Madhavan Unny, $\mathrm{N}^{2}$ \\ ${ }^{I}$ (Department of Veterinary Epidemiology and Preventive Medicine, College of Veterinary and Animal Sciences, \\ Kerala Veterinary and Animal Sciences University, Mannuthy, Thrissur, Kerala, India) \\ ${ }_{2}^{2}$ (Department of Veterinary Clinical Medicine, College of Veterinary and Animal Sciences, Kerala Veterinary \\ and Animal Sciences University, Mannuthy, Thrissur, Kerala, India)
}

\begin{abstract}
A rare case of Jatropha multifida poisoning in a adult Malabari goat is reported. Clinical signs were related to the gastrointestinal system with diarrhea and resultant dehydration. Perusal of literature did not reveal any report of Jatrapha multifida poisoning in animals in India.
\end{abstract}

Keywords: Goat, Jatropha multifida poisoning

\section{Introduction}

Jatropha is a nonedible oil seed plant belonging to Euphorbiaceae family. The Spurge family (Euphorbiaceae) is a large family of flowering plants with 321 genera and around 7550 species [1]. The genus Jatropha is widespread in the tropical regions of the world such as Americas, Africa and parts of the Asian subcontinent. The major toxic principle in Jatropha seeds are phorbol esters [2]. J. multifida is a large shrub with distinctive large dark green leaves cut deeply into 7-11 narrow lobes, margins of each lobe being dissected into narrow pointed segments. The fruits are three lobed, $2.5 \mathrm{~cm}$ long, smooth and yellowish. [3]. Perusal of literature did not reveal any report of Jatropha multifida poisoning in animals in India.

\section{Case Study}

A three year old $30 \mathrm{~kg}$ Malabari doe was presented to University Veterinary Hospital Kokkalai, Thrissur, with the history of anorexia, weakness, diarrhoea and lethargy that had progressively worsened over the preceding two days. During history collection, it was revealed that the animal had consumed a particular plant, which the owner was not familiar with, from a new grazing area for the last two days. On examination, the animal was dull and depressed. Dehydration was evident on skin tenting examination along with moderately sunken eyeballs (Fig. 1). On clinical examination, the rectal temperature of the goat was $103.0^{\circ} \mathrm{F}$ and rumen motility was 2 per minute. Feacal sample was negative for ova of parasites. The owner was asked to bring the plant sample and he brought the same and informed that there were fruits also in these plants. The plant was identified with expert support as Jatropha multifida (Fig. 2). A tentative diagnosis of J. multifida toxicosis was made based on the history of grazing these plants and presence of characteristic gastrointestinal signs which have been reported [4]. The case was treated symptomatically with lactated Ringer's solution $300 \mathrm{ml}$ followed by $5 \%$ dextrose $500 \mathrm{ml}$ (slow intravenous) along with B complex injection (Inj. Beplex forte $1 \mathrm{ml}$ intramuscularly). A single dose of activated charcoal ( $2 \mathrm{~g} / \mathrm{kg}$ orally) was also given. Treatment was continued for three days and complete recovery was observed.

\section{Discussion}

It has been opined that history of consumption of plant and seed and positive identification of ingested plant as Jatropha is a must for diagnosing toxicity in ingested animals in case of J.curcas poisoning[5]. Phytotoxins are absorbed from the gastrointestinal tract in appreciable quantities to result in poisoning. The toxicity of J. multifida is attributed to its seeds. The seeds are known to contain two main toxins that could lead to clinical signs after ingestion. The first type includes a variety of diterpenoid esters, including the tiglianetype, such as citlalitrione, curcusones, and riolozatrione [6]. These toxins have been shown by in vitro studies to have the potential to cause cardiac and respiratory depression. The second toxin type is known as toxalbumins, which are proteins known to inhibit protein synthesis, similar to the effects of ricin [7]. It has been reported that that curcin and phorbol esters are the two main substances that have been associated with the toxicity of Jatropha species[8]. Phorbol esters are the most toxic molecules in Jatropha species. The clinical signs in the present study could be attributed to the effects of both these toxins. Acute toxicity in goat due to Jatropha curcas seeds were reported when given at a dose ranging between 0.25 to $10 \mathrm{~g} / \mathrm{kg} / \mathrm{day}$ [9]. During dosing period, symptoms like diarrhoea and loosing ability to keep normal posture were seen in the goat and mortality occurred between day 7 and 21 after extract administration. In a study conducted, sheep receiving pericarp of Jatropha curcas in $15 \%$ concentration, after 10 days of pericarp ingestion produced decrease in food intake, diarrhoea, dehydration and loss of body condition[10]. Similar findings were reported in another study ie. profused diarrhoea, rapid respiration and abdominal pain, salivation, moaning, anorexia, reduced water intake, ataxia and recumbency in Jatropha toxicity[11]. It was found that animals usually limit their intake of plants 
containing toxins through feedback mechanisms that link the body with the palate [12]. Toxins exert adverse effects on the body that feedback via various nerves to the palate, which in turn enables animals to satiate/stop eating a particular food. This toxin satiation threshold is specific to various toxins or a combination of toxins and nutrients. In this case the animal might have stopped feeding of toxic plant based on above principle and supportive treatment hastened the recovery within three days. The possibility of poisoning with Jatropha multifida should be borne in mind while treating cases with signs suggestive of such poisoning when ruminants are presented from areas with Jatropha multifida in grazing areas.

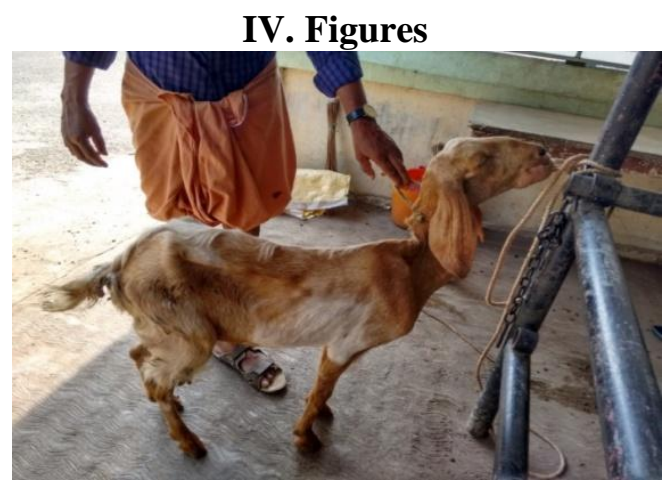

Fig.1 Goat suffering from marked depression, dehydration and weakness after ingestion of Jatropha muiltifida

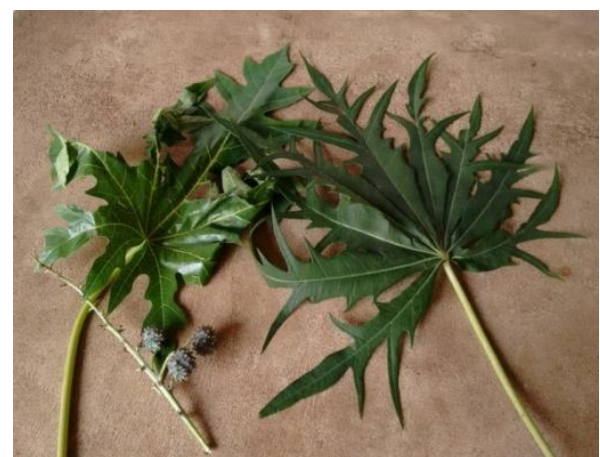

Fig, 2. Leaves of Jatropha multifida with dried fruits brought by the farmer

\section{Conclusion}

A report of plant poisoning in a Malabari goat with Jatropha multifida, the clinical signs of importance and the treatment adopted is discussed. Jatropha multifida poisoning in ruminants in India has not been reported.

\section{Acknowledgements}

The authors wish to thank the authorities of University Veterinary Hospital, Kokkalai, Thrissur for the facilities provided.

\section{References}

[1]. Rahman, A.H.M.M and Akter, M. 2013. Taxonomy and Medicinal Uses of Euphorbiaceae (Spurge) Family of Rajshahi, Bangladesh. Research in Plant Sciences 1:74-80.

[2]. Makkar, H.P.S. and Becker, K. 1998. Jatropha curcas toxicity: Identification of toxic principle(s), In: Toxic Plants and Other

[3]. Natural Toxicants. Garland, T. and Barr, A.C.(Eds.), CAB International, New York, USA, pp. 554-558.

[4]. Lucas, G. N and De Silva T.U N. 2006. Poisonous plants of Sri Lanka. Sri Lanka College of Pediatricians, Colombo, pp 25.

[5]. Pimentel, L.A., Riet-Correa, B., Dantas, A.F., Medeiros, R.M.T and Riet-Correa, F. 2012. Poisoning by Jatropha ribifolia in goats. Toxicon $59: 587-591$

[6]. Shukla. A., Singh, S.P and Tiwari. S. 2015. Transformation of toxic potential of Jatropha curcas (Ratanjyot) into protein source: A mini-review. Journal of Advances in Veterinary Animal Research 2: 89-94

[7]. Burrows, G.E and Tyrl, R.J. 2001.Toxic plants of North America. Iowa State University Press, Ames, pp. 576-584.

[8]. Butler. J. (2014). Jatropha multifida toxicosis in a dog. Veterinary Medicine 109: 188-190,192.

[9]. Makkar, H. P. S., Becker, K., Sporer, F and Wink, M. 1997. Studies on nutritive potential and toxic constituents of different provenances of Jatropha curcas. Journal of Agricultural and Food Chemistry 45:3152-3157.

[10]. Abdel-Gadir, W.S.A., Onsa, T.O and Ali, W.E.M. 2003. Comparative toxicity of Croton macrostachys, Jatropha curcas and Piper abyssinica seeds in Nubian goats. Small Ruminant Research 48 : 61-67.

[11]. Ferreira, O.R., Brito1.,S.S, Lima, F.G and Souza, D.P.M. 2012. Jatropha curcas pericarp toxicity in sheep. The Arquivo Brasileiro de Medicina Veterinária e Zootecnia. 64:559-567

[12]. Onsa, T.O., Adam, S. E. I. and Hussain, A. M. 2008. Effect of combined oral administration of Jatropha curcas seeds and Hibiscus trionum dry shoots in Nubian male goats. Sudan Journal of Veterinary Research. 23:59-64.

[13]. Provenza, F. D., Pfister, J. A. and Cheney, C. D. 1992. Mechanisms of learning in diet selection with reference to phytotoxicosis in herbivores. Journal of Range Management Archives 45:36-45. 